\title{
Association between excision repair cross-complementation group 1 polymorphism and clinical outcome of platinum-based chemotherapy in patients with epithelial ovarian cancer
}

\author{
Sokbom Kang ${ }^{1}$, Woong $\mathrm{Ju}^{2}$, \\ Jae Weon Kim ${ }^{3,4,5,6,7}$, Noh-Hyun Park ${ }^{3,4}$, \\ Yong-Sang Song ${ }^{3,4}$, Seung Cheol Kim, ${ }^{2,6}$, \\ Sang-Yoon Park ${ }^{1,6}$, Soon-Beom Kang ${ }^{3,4,6}$ \\ and Hyo-Pyo Lee Le $^{3,4}$
}

\author{
${ }^{1}$ Research Institute and Hospital \\ National Cancer Center \\ Goyang, Gyeonggi-do 410-769, Korea \\ ${ }^{2}$ Department of Obstetrics and Gynecology \\ Ewha Womans University \\ Seoul 158-710, Korea \\ ${ }^{3}$ Department of Obstetrics and Gynecology \\ ${ }^{4}$ Cancer Research Institute \\ ${ }^{5}$ Human Genome Research Institute \\ Seoul National University \\ Seoul 151-742, Korea \\ ${ }^{6}$ Clinical Research Center for Solid Tumors \\ Goyang, Gyeonggi-do 410-769, Korea \\ ${ }^{7}$ Corresponding Author: Tel, 82-2-2072-3511; \\ Fax, 82-2-762-3599; E-mail, kjwksh@snu.ac.kr
}

\section{Accepted 8 December 2005}

Abbreviations: $\mathrm{Cl}$, confidence interval; EOC, epithelial ovarian cancer; ERCC1, excision repair cross-complementation group 1; $\mathrm{OR}$, odds ratio

\begin{abstract}
ERCC1 is a DNA repair gene and has been associated with resistance to DNA damaging agents. In this study we hypothesized that a polymorphism of ERCC1 Asn118Asn $(C \rightarrow T)$ might affect the platinum-resistance of epithelial ovarian cancer patients to platinum-taxane chemotherapy administered postoperatively. Using the SNapShot assay, we assessed this polymorphism in ERCC1 in 60 ovarian cancer patients. Platinum-resistance was defined as progression on platinum-based chemotherapy or recurrence within 6 months of completing therapy. Although not significant, platinum-resistance was less frequently observed in patients with the $C / T+T / T$ genotype $(P=0.064)$. Multivariate analysis showed that the $C / T+T / T$ genotypes constituted an independent predictive factor of reduced risk of pla-
\end{abstract}

tinum-resistance in ovarian cancer (odds ratio 0.17 , $95 \%$ confidence interval 0.04-0.74, $P=0.018$, Fisher's exact test). No significant correlation was observed between overall survival and the ERCC1 polymorphism. Our results suggest that genotyping of the ERCC1 polymorphism Asn118Asn may be useful for predicting the platinum-resistance of epithelial ovarian cancer patients. However, these findings require prospective confirmation.

Keywords: DNA repair; drug resistance, neoplasm; ERCC1 protein, human; ovarian neoplasms; polymorphism, single nucleotide

\section{Introduction}

Epithelial ovarian cancer (EOC) is a leading cause of death from gynecological malignancies and the fifth most common malignancy among Korean women (Gloeckler et al., 2003). It is well known that EOC patients who initially respond to platinum-based chemotherapy can achieve objective tumor regression in response to the same or similar chemotherapy programs if the disease subsequently recurs (Markman et al., 1991). Because of the relevance of this biological feature and because it can significantly influence the choice of therapy, platinumresistance was frequently defined as progression on platinum-based chemotherapy or recurrence within 6 months of completing therapy. Platinum agents are known to act through via the formation of interstrand and intrastrand DNA cross-links, which inhibit DNA replication and/or transcription (Zamble et al., 1995). Thus, DNA repair capacity is clearly an important determinant of resistance to platinum agents.

ERCC1 (excision repair cross-complementation group 1) is one of the genes that have been most extensively investigated with regard to the association between DNA repair capacity and platinumresistance. A number of studies have suggested that ERCC1 mRNA levels are significantly correlated with cisplatin resistance in various human cancer cell lines and in a xenograft model (Britten et al., 2000; Selvakumaran et al., 2003). Moreover, it was reported that the expression levels of ERCC1 in EOC tumor tissue are significantly associated with a response to platinum-based therapy (Dabholkar et al., 1992). Similarly, the mRNA levels of ERCC1 
were reported to be significantly associated with the response to cisplatin and fluorouracil chemotherapy in gastric cancer patients (Metzger et al., 1998).

Recently, it was noted that the codon $118 \mathrm{C} / T$ polymorphism (rs11615) is associated with differential mRNA levels (Yu et al., 2000; Park et al., 2003) and has been found to be associated with shorter overall survival for advanced colorectal cancer patients treated with platinum-based chemotherapy (Park et al., 2003). So, we hypothesized that this polymorphism in ERCC1 might affect the platinum-resistance of EOC patients. In this study, we retrospectively explored the possible association between this polymorphism in ERCC1 and resistance to first-line platinum-taxane chemotherapy in EOC patients.

\section{Materials and Methods}

\section{Patients population and clinical data}

The present study involved 60 EOC Korean patients who were treated with platinum-based chemotherapy between April, 1996 and July, 2002 at Seoul National University Hospital. Eligible patients had a histologic diagnosis of EOC with adequate surgical staging, and received first-line platinum-taxane chemotherapy after surgery. All research was conducted with informed patient consent and the approval of the Institutional Review Board of Seoul National University Hospital. For genotyping, $10 \mathrm{ml}$ of peripheral blood was obtained from all subjects. All patients were staged according to the 1987 criteria recommended by the International Federation of Gynecology and Obstetrics (FIGO). Histologic slides were reviewed by two pathologists without any knowledge of the clinical data. After primary debulking surgery, the patients received 6 cycles of chemotherapy consisting of a standard regimen of carboplatin (AUC 5 every 3 weeks) and paclitaxel $\left(175 \mathrm{mg} / \mathrm{m}^{2}\right.$ every 3 weeks). All clinical data were assessed without knowledge of the genotype status. Platinum-resistance was defined as progression on platinum-based chemotherapy or recurrence within 6

Table 1. Clinical characteristics and ERCC1 polymorphisms according to platinum-resistance (PFI $<6$ months).

\begin{tabular}{|c|c|c|c|c|c|c|}
\hline & \multirow{2}{*}{$\begin{array}{c}\text { Resistant } \\
\text { (PFI }<6 \text { months }) \\
(n=20)\end{array}$} & \multirow{2}{*}{$\begin{array}{c}\text { Not resistant } \\
\text { (PFI } \geq 6 \text { months }) \\
(n=40)\end{array}$} & \multicolumn{2}{|c|}{ Univariate } & \multicolumn{2}{|c|}{ Multivariate $^{\dagger}$} \\
\hline & & & $P^{*}$ & OR & $95 \% \mathrm{Cl}$ & $P$ \\
\hline \multicolumn{7}{|l|}{ Age } \\
\hline Median & 49 & 52 & 0.298 & & & \\
\hline Range & $15-73$ & $36-67$ & & & & \\
\hline \multicolumn{7}{|l|}{ Stage } \\
\hline$|-I|$ & $2(10.0)$ & $13(32.5)$ & 0.067 & 1.00 & & \\
\hline III-IV & $18(90.0)$ & $27(67.5)$ & & 5.58 & $0.92-33.79$ & 0.061 \\
\hline \multicolumn{7}{|l|}{ Histology } \\
\hline Serous & $15(75.0)$ & $23(57.5)$ & 0.258 & & & \\
\hline Non-serous & $5(25.0)$ & $17(42.5)$ & & & & \\
\hline \multicolumn{7}{|l|}{ Grade } \\
\hline I & $3(15.0)$ & $10(25.0)$ & 0.513 & & & \\
\hline II-III & $17(85.0)$ & $30(75.0)$ & & & & \\
\hline \multicolumn{7}{|l|}{ Residual mass } \\
\hline Less than $2 \mathrm{~cm}$ & $8(40.0)$ & $32(80.0)$ & 0.002 & 1.00 & & \\
\hline $2 \mathrm{~cm}$ and over & $12(60.0)$ & $8(20.0)$ & & 7.44 & $1.88-29.49$ & 0.003 \\
\hline \multicolumn{7}{|l|}{ ERCC1 Asn118Asn } \\
\hline$C / C$ & $15(75.0)$ & $20(50.0)$ & $0.132^{\neq}$ & 1.00 & & \\
\hline$C / T$ & $5(25.0)$ & $16(40.0)$ & & 0.23 & $0.05-0.99$ & 0.049 \\
\hline$T / T$ & $0(0)$ & $4(10.0)$ & & - & & \\
\hline$C / T+T / T$ & $5(25.0)$ & $20(50.0)$ & 0.064 & 0.17 & $0.04-0.74$ & 0.018 \\
\hline
\end{tabular}

$\mathrm{OR}$, odds ratio; $\mathrm{Cl}$, confidence interval. ${ }^{*} P$-value was obtained using Fisher's exact test and Mann-Whitney test, ${ }^{\dagger}$ Logistic regression analysis was used for multivariate analysis, ${ }^{\dagger}$ Linear association was confirmed, $P_{\text {trend }}=0.047$. 
months of completing therapy. Overall survival (OS) was defined as the time interval between the date of surgery and the date of death. The platinum-free interval (PFI) was defined as the interval between treatment commencement and the date when evidence of recurrence was obtained. The detailed characteristics of the case subjects are described in Table 1.

\section{Genotyping}

Genomic DNA was extracted using conventional methods. Genotypes were assayed using a single base primer extension assay and a SNaPShot assay kit $(\mathrm{ABI})$. Briefly, the genomic region containing the SNP Asn118Asn in ERCC1 was amplified by PCR using the 5-AGGAGGGAGGAGGTGTGG (forward) and 5-AACACAGGGTCCCACCAA (reverse) primer pairs. The PCR conditions used were 1 cycle for 10 min at $95^{\circ} \mathrm{C}$, and then 30 cycles for $30 \mathrm{~s}$ at $95^{\circ} \mathrm{C}, 1$ min at $65^{\circ} \mathrm{C}, 1 \mathrm{~min}$ at $72^{\circ} \mathrm{C}$, followed by 1 cycle for 7 min at $72^{\circ} \mathrm{C}$. After amplification, the PCR products were treated with $2.0 \mathrm{U}$ of SAP (shrimp alkaline phosphatase) and $2.0 \mathrm{U}$ of EXO I (exonuclease I) for $60 \mathrm{~min}$ at $37^{\circ} \mathrm{C}$ and for $15 \mathrm{~min}$ at $72^{\circ} \mathrm{C}$ to remove the unincorporated primers and nucleotides. The SNP genotyping primers for ERCC1 Asn118Asn (5-ACTGAAGTTCGTGCGCAA) were added to the purified PCR products with an appropriate amount of SNaPShot mix and cycled on a PCR machine for 25 cycles of $10 \mathrm{~s}$ at $96^{\circ} \mathrm{C}, 5 \mathrm{~s}$ at $50^{\circ} \mathrm{C}, 30 \mathrm{~s}$ at $60^{\circ} \mathrm{C}$. A half $u$ of SAP was added to the product, followed by incubation for $60 \mathrm{~min}$ at $37^{\circ} \mathrm{C}$ and then $15 \mathrm{~min}$ at $72^{\circ} \mathrm{C}$. The final products were analyzed on an $\mathrm{ABI}$ 3700 automated sequence analyzer.

\section{Statistical analysis}

Fisher's exact test and the Mann-Whitney test were used to compare the genotypes and clinicopathological variables of resistant and non-resistant patients. Then, multivariate logistic regression analysis was performed to adjust for confounders and age. Kaplan-Meier curves were constructed in order to investigate survival difference between the wildtype and variant genotypes. Differences were tested for statistical significance using the log-rank test.

\section{Results}

A total of 60 patients with a median age of $50 \mathrm{yrs}$ (range: $15-73 \mathrm{yrs}$ ) were evaluated in this study. The median follow-up period for these 60 patients was 33.8 months (range 3.1-60.8). The allele frequencies of the ERCC1 gene among the case subjects were C, 0.76: T, 0.34, and these were in Hardy-Weinberg

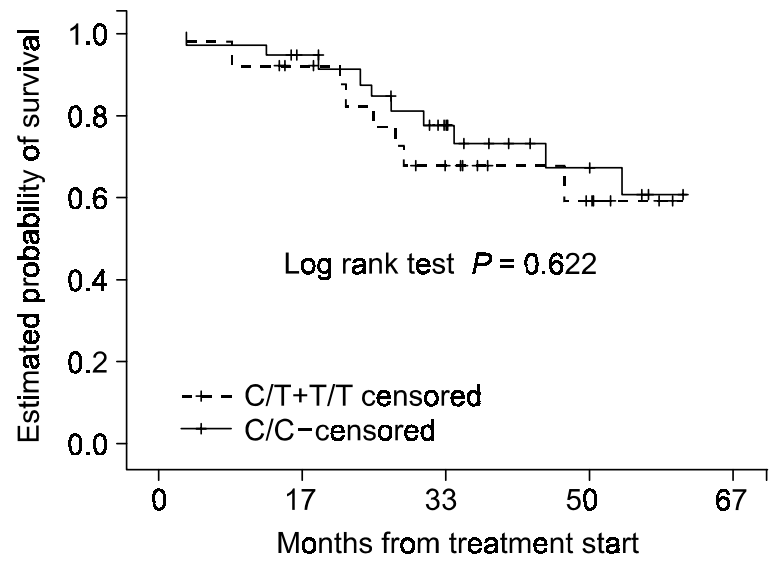

Figure 1. Comparison of overall survival in the ERCC1 codon $118 \mathrm{C} / \mathrm{C}$ genotype group and the $C / T+T / T$ genotype group in the 60 ovarian cancer patients who received first-line postoperative platinum-taxane combination chemotherapy.

equilibrium. The frequency distribution of the genotypes and the clinicopathological characteristics of the patients are shown in Table 1.

No significant associations were observed between this polymorphism and any of the clinicopathological variables (age, tumor stage, tumor histology, tumor grade, size of residual mass). The strength of the association between platinumresistance, as represented by a PFI of less than 6 months, and the ERCC1 polymorphism is presented in Table 1. Although marginally significant, stage and the presence of variant genotypes $(C / T$ or $T / T)$ were both associated with platinum-resistance. Moreover, we observed a significant linear trend among these genotypes $\left(P_{\text {trend }}=0.047\right)$. Multivariate analysis showed that those with the $C / T+T / T$ genotype were significantly associated with a reduced risk of platinum-resistance (OR 0.17, 95\% Cl 0.04-0.74).

OS was compared between those with $C / C$ and those with $C / T+T / T$, but no significant difference in OS was observed between patients in these two genotype groups $(P=0.622$, Log rank test; Figure 1). In addition, it was also observed that overall PFI was not significantly different for these two patient groups ( $P=0.268$, Log rank test).

\section{Discussion}

Optimal chemotherapeutic treatment would allow clinicians to maximize the benefits of cancer chemotherapy. Since successful first-line chemotherapy following initial surgery is crucial for a favorable outcome in ovarian cancer, many prognostic and predictive markers have been investigated to individualize treatment, maximize therapeutic effect, 
and minimize treatment toxicity. In the present study, resistance to platinum-based chemotherapy is more frequently observed in ovarian cancer patients with the ERCC1 C/C genotype.

The precise mechanism underlying the association between this polymorphism of ERCC1 codon 118 with platinum-based chemotherapy is unclear. This mutation was a $\mathrm{C} \rightarrow \mathrm{T}$ transition, coding the same amino acid: asparagine. Previously, Yu et al. reported that this transition converts a common codon usage (AAC) to an infrequent codon usage (AAT), whereas frequency of use is reduced two-fold (1997). They also described that the ovarian cancer cells with codon $118 \mathrm{C} \rightarrow \mathrm{T}$ polymorphism showed markedly reduced ERCC1 mRNA compared with cells without $\mathrm{C} \rightarrow \mathrm{T}$ transition (Yu et al., 2000). This could be possible explanation of the association between the ERCC1 codon $118 \mathrm{C} \rightarrow \mathrm{T}$ transition and the ERCC1 activity. Since much evidence has been presented concerning the association between low ERCC1 mRNA expression and increased platinum-sensitivity, those studies support our finding that EOC patients with the $C / C$ genotype have a higher risk of platinum-resistance (Dabholkar et al., 1992; Metzger et al., 1998). However, the functional importance of ERCC1 codon 118 polymorphism is still at debate. Recently, it was reported a trend toward higher intratumoral ERCC1 mRNA levels with an increasing number of $T$ alleles in a study of 31 advanced colorectal cancer patients (Stoehlmacher et al., 2004). Therefore, this association between the ERCC1 polymorphism and its mRNA levels needs further confirmation.

In our study, ERCC1 codon 118 polymorphism was not associated with OS for advanced EOC patients. It is consistent with the result of recent study describing that the ERCC1 codon 118 polymorphism was not associated with the overall survival of advanced NSCLC patients treated with platinum- based chemotherapy (Zhou et al., 2004). However, there were a number of studies describing that this polymorphism of ERCC1 is associated with the overall survival of cancer patients treated with chemotherapy. In NSCLC, the ERCC1 codon 118 $C / C$ genotype was reported to be associated with improved survival in patients with lung cancer (Ryu et al., 2004). In colon tumors, the ERCC1 codon 118 C/C genotype was associated with a favorable survival outcome (Stoehlmacher et al., 2004).

This discrepancy might be due to insufficient sample size of the present study. However, it might be speculated that the conflicting data can be due to the diverse roles of platinum chemotherapy in the patients' hospital course. For patients who receive salvage chemotherapy, i.e., patients who are at the end of their hospital course, response to chemo- therapy has a crucial impact on survival. On the other hand, as in the case of EOC, other factors have a greater opportunity to interfere with survival outcome because patients receive platinum-based chemotherapy as their $1^{\text {st }}$ line treatment.

Interestingly, although we observed a statistically significant relation between the $C / C$ genotype and a $\mathrm{PFI}$ of less than 6 months, we found that overall PFI was not statistically different between those with $C / C$ and those with $C / T$ or $T / T$, which may be due to an association between this ERCC1 polymorphism and resistance to platinum chemotherapy, but not with the maintenance of a prolonged disease-free state. Another possible explanation is that platinum-taxane synergism may interfere with the relationship between overall PFI and the ERCC1 polymorphism.

The present study has several limitations. First, the small sample size of cases made it difficult to exclude the possible association between ERCC1 polymorphism and OS of EOC patients. Second, since platinum-paclitaxel combination treatment is the standard treatment for managing ovarian cancer patients, the synergistic effect of paclitaxel may have biased our results. And finally, functional data supporting the association between the ERCC1 polymorphism and its activity are still controversial and insufficient.

In conclusion, our findings can be the one of preliminary data suggesting that the ERCC1 Asn118Asn polymorphism predicts resistance to platinum-based chemotherapy in EOC patients. Because, to our knowledge, this is the first study to report an association between the ERCC1 polymorphism and resistance to platinum-based chemotherapy in EOC, a large-scale prospective clinical trial is needed to validate the possible relationship between the ERCC1 polymorphism and response to platinum agents.

\section{Acknowledgement}

This work was supported partly by a grant from the Korea Science and Engineering Foundation (R002004-000-10561-0), partly by a grant of the Korea Health 21 R\&D Project, Ministry of Health \&Welfare, Republic of Korea (0412-CR01-0704-0001) and partly by a grant from the Seoul National University Hospital Research Fund (\#21-2005-007).

\section{References}

Britten RA, Liu D, Tessier A, Hutchison MJ, Murray D. ERCC1 expression as a molecular marker of cisplatin resistance in human cervical tumor cells. Int $\mathrm{J}$ Cancer 2000;89:453-7

Dabholkar M, Bostick-Bruton F, Weber C, Bohr VA, Egwuagu 
C, Reed E. ERCC1 and ERCC2 expression in malignant tissues from ovarian cancer patients. J Natl Cancer Inst 1992;84:1512-7

Gloeckler Ries LA, Reichman ME, Lewis DR, Hankey BF, Edwards BK. Cancer survival and incidence from the Surveillance, Epidemiology, and End Results (SEER) program. Oncologist 2003;8:541-52

Markman M, Rothman R, Hakes T, Reichman B, Hoskins W, Rubin S, Jones W, Almadrones L, Lewis JL Jr. Second-line platinum therapy in patients with ovarian cancer previously treated with cisplatin. J Clin Oncol 1991;9:389-93

Metzger R, Leichman CG, Danenberg KD, Danenberg PV, Lenz HJ, Hayashi K, Groshen S, Salonga D, Cohen H, Laine L, Crookes P, Silberman H, Baranda J, Konda B, Leichman L. ERCC1 mRNA levels complement thymidylate synthase mRNA levels in predicting response and survival for gastric cancer patients receiving combination cisplatin and fluorouracil chemotherapy. J Clin Oncol 1998;16:309-16

Park DJ, Stoehlmacher J, Zhang W. ERCC1 polymorphism is associated with differential ERCC1 gene expression. Proc Am Assoc Cancer 2002;1591

Park DJ, Zhang W, Stoehlmacher J. ERCC1 gene polymorphism as a predictor for clinical outcome in advanced colorectal cancer patients treated with platinum-based chemotherapy. Clin Adv Hematol Oncol 2003;1:162-6

Ryu JS, Hong YC, Han HS, Lee JE, Kim S, Park YM, Kim YC, Hwang TS. Association between polymorphisms of ERCC1 and XPD and survival in non-small-cell lung cancer patients treated with cisplatin combination chemotherapy. Lung Cancer 2004:44:311-6

Selvakumaran M, Pisarcik DA, Bao R, Yeung AT, Hamilton TC. Enhanced cisplatin cytotoxicity by disturbing the nucleotide excision repair pathway in ovarian cancer cell lines. Cancer Res 2003;63:1311-6

Stoehlmacher J, Park DJ, Zhang W, Yang D, Groshen S, Zahedy S, Lenz HJ. A multivariate analysis of genomic polymorphisms: prediction of clinical outcome to 5-FU/ oxaliplatin combination chemotherapy in refractory colorectal cancer. Br J Cancer. 2004;91:344-54

Yu JJ, Lee KB, Mu C, Li Q, Abernathy TV, Bostick-Bruton F, Reed E. A nucleotide polymorphism in ERCC1 in human ovarian cancer cell lines and tumor tissues. Mutat Res 1997;382:13-20

Yu JJ, Lee KB, Mu C, Li Q, Abernathy TV, Bostick-Bruton F, Reed $\mathrm{E}$. Comparison of two human ovarian carcinoma cell lines (A2780/CP70 and MCAS) that are equally resistant to platinum, but differ at codon 118 of the ERCC1 gene. Int $J$ Oncol 2000;16:555-60

Zamble DB, Lippard SJ. Cisplatin and DNA repair in cancer chemotherapy. Trends Biochem Sci 1995;20:435-9

Zhou W, Gurubhagavatula S, Liu G, Park S, Neuberg DS, Wain JC, Lynch TJ, Su L, Christiani DC. Excision repair cross-complementation group 1 polymorphism predicts overall survival in advanced non-small cell lung cancer patients treated with platinum-based chemotherapy. Clin Cancer Res 2004;10:4939-43 